\title{
WHAT DO THEY KNOW ABOUT HIVIAIDS - ADOLESCENTS AND YOUNG ADULTS FROM SLUMS IN MUMBAI, INDIA
}

\author{
Velhal G, Kambli TD, Suryawanshi SR, \\ Department of Preventive \& Social Medicine, Topiwala National Medical College \& B. Y. L. Nair Ch Hospital \\ Mumbai - 400 008, Maharashtra state, India
}

\begin{abstract}
Introduction: In compliance with guidelines from NACP III, wide spread activities are continued, by public, private and NGO sectors, to enhance the level of knowledge about HIVIAIDS among vulnerable adolescent and young adult population in urban areas, in the forms of various projects, so as to facilitate positive behavioural changes among them . Present cross-sectional study, was conducted in three, representative administrative wards (namely L, K/East \& R/North) of Municipal Corporation of Greater Mumbai (MCGM), India, in December 2010, to assess the level of knowledge and attitudes about HIVI AIDS amongst the adolescents and young adults.
\end{abstract}

Methodology: Total 4306, adolescents and young adults representing all 28 health posts from selected wards were interviewed by 100 trained NSS volunteers of University of Mumbai, under the leadership of Department of Community Medicine, T. N. Medical College \& Nair Hospital. Data was analysed with the help of statistical software (SPSS).

Results: Seventy-nine percent (3407/4306) and 49.81\% (2145/4306), of respondents had heard about HIVIAIDS, and STI/RTIs respectively. Unsafe sexual relationship, as route of transmission is known to $51.81 \%$ (2231/4306) respondents, whereas use of condom, as preventive measure is known to $87 \%$ (3746) of people. Only $30.05 \%$ (1294/4306) respondents know nearby testing facilities. Everybody should be tested for HIV, to reduce transmission, is believed by $93.96 \%$, (4046/4306) respondents. Knowledge grade given to each respondent based on the score obtained by them out of total obtainable 25 score, reveals, $57.36 \%$, (2470/4306), in poor grade. Multinomial logistic regression confirms the significant influence of age and education status of respondents on their knowledge and positive attitudes.]

Conclusion: When compared with other relevant studies, the present status of knowledge of adolescents and young adults from slums of Mumbai appears to be poor and justifies the need for intensified efforts towards improving the same, taking into account their vulnerability. Well planned coordinated efforts of public, private and NGO sectors, would go a long way to get the desired impact.

Key words: HIVIAIDS, Adolescents, Young adults, Knowledge, Attitudes

\section{INTRODUCTION}

HIVIAIDS is the biggest public health challenges

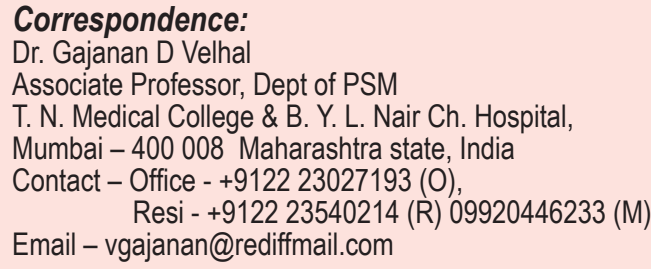

in the world today. Even though the prevalence of HIV infection is showing declining trend in present times, globally, estimated 33.2 Million individuals are infected with HIV so far and total number of 2.1 million deaths are reported since the identification of first case of HIVIAIDS, in US in the year 1981. In Asia, an estimated 4 million people are living with HIVIAIDS, in 2007. ${ }^{1}$ Taking into account number of people living with HIVIAIDS, India, ranks second, in the world and has estimated 22.7 lakh HIV infected 
people with an estimated $0.29 \%$ prevalence rate, among general public, at the end of $2008 .{ }^{2}$ State of Maharashtra, has the identity of high prevalence state in the country with ANC prevalence rates as high as, $0.5 \%$. Mumbai is said to be the epicentre of the epidemic in Maharashtra.

Young people are especially vulnerable to HIV infection, more so if they belong to slum areas. Although young people, 15-24 years of age, account for $45 \%$ of all new HIV infections in adults, many young people still lack access to adequate health information and services. ${ }^{1}$ Around the world empowering youth (aged 15-25 years) with the information and skills to protect themselves and their families from HIV infection is considered one of the best long term strategies to contain the HIVI AIDS epidemic. The youth in the age group 1525 years, usually incorporates two categories, adolescents (15 - 18 years) and young adults (1925 years). Adolescent stage, represent transition from puberty to adulthood, while young adult stage represents adoption to mature, responsible adulthood, and hence influencing behaviour pattern of this youth group with wide spread advocacy, communication and social mobilization activities would yield great result.

Studies on knowledge, attitude, behaviour and practices (KABP), conducted in different parts of India, reveal widespread ignorance and misconceptions about the disease among adolescents. Efforts are intensified in compliance with guidelines from NACP III, by public, private and NGO sectors, to enhance the level of knowledge about HIVIAIDS among vulnerable adolescent and young adult population in urban areas, in the forms of various projects. Present study was undertaken to assess the level of knowledge and attitudes about HIVIAIDS, among adolescents and young adults (15 - 24 years), from slum areas of Mumbai, India, to understand the impact of IEC activities, so far in this respect, and identify the scope for further improvement to sustain declining trend of HIV epidemic.

\section{METHODOLOGY}

Present community based, descriptive epidemiological study, carried out in December 2010 , adopted cross sectional exploratory survey design, to assess the knowledge and attitudes of adolescents and young adults (15-25 years) about HIVIAIDS, from slum areas in Mumbai, India. Three representative administrative wards (L, K/East \& R/ North) were randomly selected, out of total 24 wards under Municipal Corporation of Greater Mumbai. Total slum population of these 3 wards together is 20.3 lakhs, out of which $20 \%$ belong to the age group of 15-25 years. For the purpose of health care delivery, each ward is divided into health post areas, and each health post, further divided into different sections and areas within each section. To represent entire study area, data is collected from 24 health post areas (out of total 28 health posts) in all 3 wards, which includes 75 sections (out of total 152 sections in 3 wards) and 150 areas (out of total 858 areas). Convenient sample of total 4306 respondents (Average 180 from each selected health post, adolescents, $15-18$ years, 120, and young adults, $19-25$ years, 60 ), constitutes study group subjects with adequate representation of males (2224) and females (2082).

Total number of 100 trained, National Service Scheme (NSS) volunteers of University of Mumbai, who worked in pairs, were involved in data collection by undertaking house to house survey, with the help of preformed, pre tested semi structured interview schedule, which included questions on knowledge as well as attitudes of the people about HIVIAIDS. Informed oral consent of the respondents was obtained prior to their interview. The data was analysed with the help of statistical software (SPSS,17.0 version) package, in terms responses to each question and score obtained by each respondent to the correct responses, out of maximum obtainable 25 score, for all questions. 


\section{RESULTS}

Out of total number of 4306 study subjects, who belonged to $L$ ward (1980), K/East ward (1447) and R/North ward (879), 2224, 51.65\% are males (1285 adolescents and 939 young adults) and 2082, 48.35\%, are females (1219 adolescents and 863 young adults) (Table 1). Educational status wise distribution, reveals maximum number of respondents educated up to secondary school level (2867, 66.58\%), followed by college going youths $(1234,28.66 \%)$ and rest were educated up to only primary level $(89,2.06 \%)$ or illiterate ( $116,2.70 \%)$. Overall high percentage of individuals educated up to secondary school level and above, (as against the findings of NFHS III data ${ }^{3}$ ) is mainly because of availability and accessibility of low cost education facilities extended to slum areas through MCGM run schools, and overall general awareness among the people about the importance of education, being residing in urban areas. Among the adults, $13.63 \%$ males (128/939) and $39.39 \%$ females (340/863) are married and the corresponding figures for adolescents are $2.64 \%(34 / 1285)$ and $5.17 \%(63 / 1219)$, which are much less than NFHS III data. ${ }^{3}$

Knowledge grade given to each individual is based on the score obtained by him/her, on the questions as per the interview schedule, with maximum obtainable score of 25 . Those who scored 8 or less than 8 are given poor grade, those who scored in the range of 9 to 16 , are given average grade and those who scored $17 \&$ above are given good grade. The mean knowledge score is 6.98 with the range of 0 to 19 \& Standard Deviation of 4.45 , for $L$ Ward. Similarly mean score for K/East \& R/ North wards are $6.85(\mathrm{SD}=3.64) \& 9.39(\mathrm{SD}=5.36)$ respectively. The average score obtained by all respondents is 7.74 out of 25 i.e. $30.96 \%$. The average score obtained by all in poor grade is 3.21 whereas it is 13.05 and 17.12 for those in average and good grade respectively. Poor, Average and Good grades are obtained by $2470(57.36 \%)$, $1706(39.61 \%)$ and $130(3.01 \%)$ respondents respectively (Table 2). Mean score of males $(7.73 / 25)$ is more than females (7.11/25) and it is statistically significant $(P<0.01)$. Similarly mean score in adult males (8.53) and adult females (7.73) significantly defers from their adolescent counterparts (Males - 7.14 \& Females - 6.67). Among the unmarried respondents, $57.92 \%$ (2167/3741) obtained Poor grade, $38.92 \%$ (1456/3741) obtained Average grade and only $3.16 \%$ (118/3741) obtained Good grade. Among the married individuals the corresponding figures for Poor, Average \& Good grade are 55.22\% (312/565), 42.47\% (240/565) and 2.31\% (13/565) respectively. Even though the situation apparently appears to be better for married individuals as compared to unmarried individuals, difference

\begin{tabular}{|c|c|c|c|c|c|c|c|c|c|}
\hline \multicolumn{2}{|c|}{ Table 1. Educational status of study subjects $(\mathrm{N}=4306)$} \\
\hline \multirow{2}{*}{ Sex } & \multicolumn{2}{|c|}{ Iliterate } & \multicolumn{2}{|c|}{ Primary } & \multicolumn{2}{c|}{ Secondary } & \multicolumn{2}{c|}{ College } & Total \\
\cline { 2 - 10 } & Ado & Adu & Ado & Adu & Ado & Adu & Ado & Adu & \\
\hline M & 22 & 32 & 25 & 14 & 1075 & 412 & 163 & 481 & 2224 \\
\hline F & 13 & 49 & 29 & 21 & 954 & 426 & 223 & 367 & 2082 \\
\hline Total & 35 & 81 & 54 & 35 & 2029 & 838 & 386 & 848 & 4306 \\
\hline
\end{tabular}

Ado - Adolescents, Adu - Adults

\begin{tabular}{|c|c|c|c|c|c|c|c|c|c|}
\hline \multirow{3}{*}{$\begin{array}{l}\text { Ward } \\
\text { Knowledge } \\
\text { Grade }\end{array}$} & \multicolumn{8}{|c|}{ Educational Status } & \multirow{3}{*}{ Total } \\
\hline & \multicolumn{2}{|c|}{ Illiterate } & \multicolumn{2}{|c|}{ Primary } & \multicolumn{2}{|c|}{ Secondary } & \multicolumn{2}{|c|}{ College } & \\
\hline & M & F & $\mathbf{M}$ & $F$ & M & $\mathbf{F}$ & M & $F$ & \\
\hline Poor & 28 & 45 & 25 & 39 & 891 & 923 & 244 & 275 & 2470 \\
\hline Average & 22 & 17 & 14 & 10 & 554 & 412 & 383 & 294 & 1706 \\
\hline Good & 4 & 0 & 0 & 1 & 42 & 45 & 17 & 21 & 130 \\
\hline Total & 54 & 62 & 39 & 50 & 1487 & 1380 & 644 & 590 & 4306 \\
\hline
\end{tabular}

$\chi^{2}=7.487, \mathrm{df}-1, \mathrm{P}=0.0062$, Poor \& Average/ Good grades Vs Education status $\chi^{2}=8.929, \mathrm{df}-1, \mathrm{P}<0.0001$, Poor \& Average/ Good grades Vs sex, 
is not statistically significant. There is significant difference in knowledge level between males and females, as well as among those who are educated up to primary level $(68 / 205,33.17 \%)$, Vs those educated up to secondary school level and above (1768/4101, 43.11\%), (Table 2). This indicates the influence of education level on the awareness about HIVIAIDS. Present study thus indicates the importance of focusing on non student youth.

Significantly more number of males \& adult population, have heard about HIVIAIDS $(1571 / 1802,87.18 \%)$ and STIs (1050/1802, $58.26 \%$ ) as compared to females and adolescents. (For HIVIAIDS - 1836/2504, 73.32\% and for STIs - 1095/2504, 43.73\%), (Table 3). This may be because of more exposure to the knowledge on HIVIAIDS and STIs among adults (either in college or working place, through peers or other sources) as compared to Adolescents.

\begin{tabular}{|c|c|c|c|c|}
\hline \multicolumn{4}{|c|}{ Table 3. Heard of HIVIAIDS \& STI (N = 4306) } \\
\hline \multirow{2}{*}{ Sex } & \multicolumn{2}{|c|}{ HIVIAIDS } & \multicolumn{2}{c|}{ STI s } \\
\cline { 2 - 5 } & Adolescents & Adults & Adolescents & Adults \\
\hline M & 957 & 842 & 584 & 596 \\
\hline F & 879 & 729 & 511 & 454 \\
\hline Total & 1836 & 1571 & 1095 & 1050 \\
\hline
\end{tabular}

\begin{tabular}{|l|l|l|l|}
\hline & $\chi^{2}$ & df & P value \\
\hline $\begin{array}{l}\text { Heard of HIV/AIDS Vs Adolescents } \\
\text { and adults }\end{array}$ & 120.99 & 1 & $<0.0001$ \\
\hline $\begin{array}{l}\text { Heard of STI Vs Adolescents and } \\
\text { adults }\end{array}$ & 88.017 & 1 & $<0.0001$ \\
\hline Heard of HIVIAIDS Vs sex & 8.485 & 1 & 0.0036 \\
\hline Heard of STI Vs Sex & 19.087 & 1 & $<0.0001$ \\
\hline
\end{tabular}

Table 4 shows that $34.81 \%$ (1499/4306) of study population did not know any modes of transmission of HIV. Almost $52 \%$ (2231/4306) of study population reported that they knew about unsafe sexual intercourse transmits HIV and 44.93\%, 32.60\% \& $13.93 \%$ of subjects knew about transmission of HIV by contaminated needle, contaminated blood \& parent to child transmission respectively. Findings that sharing tooth brushes $(0.18 \%)$, living with infected persons, sharing their cloths $(0.86 \%)$, contaminated air or water $(0.23 \%)$ and mosquito bite $(0.11 \%)$ can lead to infection, are indications of ignorance \& lack of awareness.

\begin{tabular}{|l|c|c|}
\hline \multirow{2}{*}{ Table 4. Modes of transmission (N=4306) } \\
\hline \multirow{2}{*}{ Modes of transmission } & \multicolumn{2}{|c|}{ Total (N=4306) } \\
\cline { 2 - 3 } & No & $\%$ \\
\hline $\begin{array}{l}\text { Unsafe sexual } \\
\text { relationship }\end{array}$ & 2231 & 51.81 \\
\hline $\begin{array}{l}\text { Contaminated needle, } \\
\text { blade }\end{array}$ & 1935 & 44.93 \\
\hline Contaminated blood & 1404 & 32.60 \\
\hline Mother to child & 600 & 13.93 \\
\hline Sharing toothbrushes & 8 & 0.18 \\
\hline $\begin{array}{l}\text { Staying together, sharing } \\
\text { personal things, towels, } \\
\text { cloths }\end{array}$ & 37 & 0.86 \\
\hline Through air \& water & 10 & 0.23 \\
\hline Mosquito bite & 5 & 0.11 \\
\hline Do not know & 1499 & 34.81 \\
\hline
\end{tabular}

Table 5 reveals that almost 87\% (3746/4306) know the use of condom as preventive measure against HIV. The number of individuals who have mentioned use of new needles by IVDUs $(748 / 4306,17.37 \%)$, use of blood from accredited blood bank (521/4306, $12.09 \%)$, Safer sex practices $(431 / 4306,10.00 \%)$ and PPTCT (115/4306, 2.67\%), are very low.

When specifically enquired to identify nearby places where diagnostic tests for HIV are done only $30.05 \%$ (1294/4306) respondents could mention them correctly (Table 6).

\begin{tabular}{|l|c|c|}
\hline \multirow{3}{*}{$\begin{array}{c}\text { Table 5. Knowledge about ways of prevention of HIV } \\
\text { infection (N=4306) }\end{array}$} \\
\hline \multicolumn{1}{|c|}{ Ways of prevention } & \multicolumn{2}{|c|}{ Total (N=4306) } \\
\cline { 2 - 3 } & No & $\%$ \\
\hline Use of condom & 3746 & 86.99 \\
\hline New needle for IVDUs & 748 & 17.37 \\
\hline $\begin{array}{l}\text { Take blood from accredited } \\
\text { blood bank }\end{array}$ & 521 & 12.09 \\
\hline $\begin{array}{l}\text { Safe sex (be faithful + } \\
\text { Abstinence) }\end{array}$ & 431 & 10.00 \\
\hline PPTCT & 115 & 2.67 \\
\hline $\begin{array}{l}\text { Not to talk/ touch infected } \\
\text { person }\end{array}$ & 33 & 0.76 \\
\hline Avoid kissing & 29 & 0.67 \\
\hline Contraceptive pills/l pills & 22 & 0.51 \\
\hline
\end{tabular}




\begin{tabular}{|c|c|c|}
\hline \multirow{2}{*}{ Table 6. Knowledge about nearest ICTC Centre } \\
\hline \multirow{2}{*}{ Nearest ICTC Centre } & \multicolumn{2}{|c|}{ Total (N = 4306) } \\
\cline { 2 - 3 } & No & $\%$ \\
\hline Know them correctly & 1294 & 30.05 \\
\hline Do not know & 2375 & 55.16 \\
\hline
\end{tabular}

Rest of the individuals (Total -637 , $L$ ward 414, K/East ward -5 \& R/North ward - 218) gave irrelevant answers to this question like any dispensary, non allopathic private practitioners, any small pathology laboratory, where routine investigations are carried out, etc.

Total number of 5 attitudinal questions as mentioned in Table 7 were asked to each respondent. The expected or correct responses given are shown in the given table. It is apparent that, more than $50 \%$ of respondents are aware about true facts and have expressed their positive attitude to the statements number 2,4 \& 5 i.e. $2276 / 4306$, 2738/4306 \& 2499/4306 respectively. However majority of the people still believe in getting everybody tested for HIV infection and around 69\% (2938/4306) individuals are not awareness about more vulnerability of women for HIV, than males. This deserves attention in the scheduled training programmes for the beneficiaries at different levels and by different organizations.

Respondents giving expected responses to the statements are significantly higher among more educated classes as compared to illiterates and those who have learned only up to primary level. Similarly, percentages of married respondents is better as compared to unmarried respondents as far as desired responses to the statements number $3 \& 4$ are concerned, as against statement 1,2 \& 5. (Table 7).

Table 7. Expected responses to attitudinal questions - education and material status wise

\begin{tabular}{|c|c|c|c|c|c|c|c|c|c|}
\hline \multirow{2}{*}{ Statement } & \multicolumn{2}{|c|}{ Illiterate } & \multicolumn{2}{|c|}{ Primary } & \multicolumn{2}{|c|}{ Secondary } & \multicolumn{2}{|c|}{ College } & \multirow{2}{*}{ Total } \\
\hline & $U$ & $M$ & U & $M$ & $U$ & $M$ & $U$ & $M$ & \\
\hline $\begin{array}{l}\text { Everybody should undergo HIV } \\
\text { testing }\end{array}$ & 0 & 3 & 0 & 2 & 159 & 18 & 70 & 8 & 260 \\
\hline $\begin{array}{l}\text { Once HIV infection is diagnosed, } \\
\text { person cannot survive at all }\end{array}$ & 22 & 21 & 26 & 15 & 1271 & 206 & 635 & 80 & 2276 \\
\hline $\begin{array}{l}\text { Women are more vulnerable to } \\
\text { HIVIAIDS }\end{array}$ & 14 & 17 & 21 & 3 & 776 & 107 & 395 & 35 & 1368 \\
\hline $\begin{array}{l}\text { People should not interact with } \\
\text { HIV infected person }\end{array}$ & 24 & 28 & 32 & 13 & 1496 & 240 & 806 & 99 & 2738 \\
\hline $\begin{array}{l}\text { No nursing care should be } \\
\text { provided to HIV infected person } \\
\text { at home }\end{array}$ & 18 & 21 & 30 & 13 & 1375 & 223 & 739 & 80 & 2499 \\
\hline
\end{tabular}

U - Unmarried, M - Married

\begin{tabular}{|c|c|c|c|c|}
\hline \multicolumn{2}{|r|}{ Statements } & \multirow{2}{*}{$\frac{\chi^{2}}{0.2002}$} & \multirow{2}{*}{$\frac{d f}{1}$} & \multirow{2}{*}{$\begin{array}{l}\text { P value } \\
0.6546\end{array}$} \\
\hline & Married Vs Unmarried & & & \\
\hline HIV testing & $\begin{array}{l}\text { Illiterates and those who have learned up to primary } \\
\text { level Vs more educated classes }\end{array}$ & 4.184 & 1 & 0.0408 \\
\hline \multirow{2}{*}{$\begin{array}{l}\text { Once HIV infection is } \\
\text { diagnosed, person cannot } \\
\text { survive at all }\end{array}$} & Married Vs Unmarried & 3.072 & 1 & 0.0797 \\
\hline & $\begin{array}{l}\text { Illiterates and those who have learned up to primary } \\
\text { level Vs more educated classes }\end{array}$ & 11.509 & 1 & 0.0007 \\
\hline \multirow{2}{*}{$\begin{array}{l}\text { Women are more vulnerable } \\
\text { to HIVIAIDS }\end{array}$} & Married Vs Unmarried & 20.472 & 1 & $<0.0001$ \\
\hline & $\begin{array}{l}\text { Illiterates and those who have learned up to primary } \\
\text { level Vs more educated classes }\end{array}$ & 2.108 & 1 & 0.1466 \\
\hline \multirow{2}{*}{$\begin{array}{l}\text { People should not interact } \\
\text { with HIV infected person }\end{array}$} & Married Vs Unmarried & 4.076 & 1 & 0.0435 \\
\hline & $\begin{array}{l}\text { Illiterates and those who have learned up to primary } \\
\text { level Vs more educated classes }\end{array}$ & 21.716 & 1 & $<0.0001$ \\
\hline \multirow{2}{*}{$\begin{array}{l}\text { No nursing care should be } \\
\text { provided to HIV infected } \\
\text { person at home }\end{array}$} & Married Vs Unmarried & 0.6961 & 1 & 0.4041 \\
\hline & $\begin{array}{l}\text { Illiterates and those who have learned up to primary } \\
\text { level Vs more educated classes }\end{array}$ & 27.688 & 1 & $<0.0001$ \\
\hline
\end{tabular}




\begin{tabular}{|l|c|c|c|c|c|c|c|}
\hline \multirow{2}{*}{\multicolumn{1}{c|}{ Responses }} & \multicolumn{5}{c|}{ Knowledge Grade } & \multirow{2}{*}{ Total } \\
\cline { 2 - 8 } & \multicolumn{2}{|c|}{ Poor } & \multicolumn{2}{c|}{ Average } & \multicolumn{2}{c|}{ Good } & \\
\cline { 2 - 7 } & $\mathrm{M}$ & $\mathrm{F}$ & $\mathrm{M}$ & $\mathrm{F}$ & $\mathrm{M}$ & $\mathrm{F}$ & \\
\hline Everybody should undergo HIV testing & 82 & 74 & 69 & 32 & 2 & 1 & 260 \\
\hline Once HIV infection is diagnosed, person cannot survive at all & 503 & 556 & 622 & 505 & 43 & 47 & 2276 \\
\hline Women are more vulnerable to HIVIAIDS & 331 & 282 & 422 & 254 & 37 & 42 & 1368 \\
\hline People should not interact with HIV infected person & 581 & 666 & 781 & 611 & 46 & 53 & 2738 \\
\hline No nursing care should be provided to HIV infected person at home & 571 & 591 & 712 & 550 & 30 & 45 & 2499 \\
\hline
\end{tabular}

M- males, F-Females

\begin{tabular}{|l|l|}
\hline $\begin{array}{l}\chi^{2}=23.168, \mathrm{df}-4, \mathrm{P}=0.0001, \text { Responses among those who have } \\
\text { obtained poor knowledge grade Vs average/good grade }\end{array}$ & $\chi^{2}=5.437, \mathrm{df}-1, \mathrm{P}=0.0197$, Statement 1, Males Vs Females \\
\hline$\chi^{2}=0.1843, \mathrm{df}-1, \mathrm{P}=0.6677$, Statement 2, Males Vs Females & $\chi^{2}=29.514, \mathrm{df}-1, \mathrm{P}<0.0001$, Statement 3, Males Vs Females \\
\hline$\chi^{2}=0.1280, \mathrm{df}-1, \mathrm{P}=0.7205$, Statement 4, Males Vs Females & $\chi^{2}=2.576, \mathrm{df}-1, \mathrm{P}=0.1085$, Statement 5 , Males Vs Females \\
\hline
\end{tabular}

It is evident from table 8 that, desired responses by the individuals to the attitudinal statements are influenced by the knowledge grade obtained by them. Those who have obtained either average or good grade have shown significantly better performances to the attitudinal questions as compared to those who have obtained poor grade. Similarly significant difference in correct responses is also observed among males and females for statements number $1 \& 3$. This indicates positive attitudinal changes towards HIVIAIDS among general public, because of IEC activities through various sources. However there is still enough scope to improve the situation still further especially related to statements 1 and 3 .

Application of two way analysis of variance, shows statistically significant difference in level of knowledge among males and females in adults and adolescents as well as in married and unmarried population. However, multinomial logistic regression confirms the influence of only age (adults more than adolescents) and education status (Secondary and above more than Primary and below) on the overall level of knowledge and attitudes about HIVIAIDS. (Table 9)

\begin{tabular}{|l|c|c|c|}
\hline \multicolumn{4}{|c|}{$\begin{array}{l}\text { Table 9 - Results of Two way ANOVA and Multinomial } \\
\text { Logistic Regression }\end{array}$} \\
\hline \multicolumn{4}{|c|}{ Two way ANOVA } \\
\hline Determinant & F & DoF & Significance \\
\hline \multicolumn{4}{|c|}{ Sex Age group } \\
\hline Sex & 21.196 & 1 & 0.000 \\
\hline Age group & 78.644 & 1 & 0.000 \\
\hline $\begin{array}{l}\text { Sex by Age } \\
\text { group }\end{array}$ & 1.338 & 1 & 0.247 \\
\hline \multicolumn{4}{|c|}{ Sex \& Marital status } \\
\hline Sex & 15.052 & 1 & 0.000 \\
\hline Marital status & 3.538 & 1 & 0.06 \\
\hline $\begin{array}{l}\text { Sex by } \\
\text { Marital status }\end{array}$ & 1.207 & 1 & 0.272 \\
\hline \multicolumn{4}{|c|}{ Multinomial Logistic Regression } \\
\hline Determinant & $\begin{array}{l}\text { OR } \\
\text { (Adjusted) }\end{array}$ & $\begin{array}{l}95 \% \\
\text { Confidence } \\
\text { Limit }\end{array}$ & P value \\
\hline $\begin{array}{l}\text { Sex (Male Vs } \\
\text { Females) }\end{array}$ & 1.419 & $0.988-2.037$ & 0.058 \\
\hline $\begin{array}{l}\text { Education } \\
\text { level }\end{array}$ & 0.998 & $1.103-2.590$ & 0.000 \\
\hline Age & 0.536 & $0.360-0.797$ & 0.002 \\
\hline Marital status & 0.815 & $0.434-1.530$ & 0.524 \\
\hline
\end{tabular}




\section{DISCUSSION}

In the present study, undertaken in December 2010, to assess the level of knowledge and attitudes about HIVIAIDS among adolescents and young adults (15 - 25 years age group) in slum areas of Mumbai city, India, total number of 4306 individuals were interviewed by 100 trained National Service Scheme volunteers of University of Mumbai. Total number of $3407(79.12 \%)$ individuals, from slum areas, have heard about HIVIAIDS, as against only $2145(49.81 \%)$ study subjects who have heard about STIs. Similar findings are made by the study conducted in Hyderabad ${ }^{4}$ among general population which reports, $80 \%$ \& $51 \%$ study subjects have heard of HIV \& STIs respectively. Around $45 \%$, Youths from Shahapur block of Thane district, also have heard of STIs. ${ }^{5}$ Studies conducted by Bhalla et el ${ }^{6}$, in Jamnagar, Gujarath among secondary school students \& Lal et el ${ }^{7}$, among college students in Kerala, reveal that almost all their respondents have heard of HIVI AIDS. This is mainly because of the difference in the study populations. In the present study the respondents are from slum areas, especially belonging to low socioeconomic profiles, who are difficult to reach. However, in this study, according to the grades given to the respondents, it is clearly found that, level of knowledge, is significantly better among those who are educated up to secondary school level and above as compared to illiterates and educated up to only primary school level (Table 2). Similar results were obtained by Sangole et el ${ }^{8}$, Sarkar P et el ${ }^{9}$, Sogarwal et el ${ }^{10}$, Bassey et el ${ }^{11}$, Sarkar $S$ et el $^{12}$, in their study where respondents with higher education had good knowledge of HIVI AIDS compared with respondents with lower level of education.

According to the NFHS III data ${ }^{3}, 94.2 \%$ males and $80.7 \%$ females from urban areas have heard of HIVIAIDS, whereas here corresponding figures for males and females are $85.38 \%$ and $77.23 \%$ respectively. Studies carried out by Chakrovarty et el ${ }^{13} \&$ Singh et el ${ }^{14}$ confirm awareness among males significantly more as compared to females. Present study also confirms desired responses, significantly more among males than females, when compared independently. This could be because of accessibility and availability of opportunities to obtain knowledge, more likely among males as compared to females, especially among slum population.

Unsafe sexual relationship is identified as the most important route of transmission of HIVIAIDS by $2231(51.81 \%)$ individuals, followed by 1935 $(44.93 \%)$ and $1404(32.60 \%)$ respondents, who identified contaminated needles and syringes and contaminated blood, responsible for the transmission. Population First's Report ${ }^{5}$, on a Knowledge, Attitude and Practice (KAP) Study of Adolescent Reproductive and Sexual Health (ARSH) issues, among youth of Thane district, reports that, according to $57 \%$ of respondents, HIV spreads through Unprotected sexual intercourse. According to the study conducted by Lal et $\mathrm{al}^{7}$, among college students, $48 \%$ of study subjects identified, unsafe sex as mode of transmission of HIV. A study done among slum-dwellers in another metropolitan city of India (Chennai), showed that $67 \%$ males and $55 \%$ females were aware of the sexual mode of transmission. ${ }^{15}$ Study conducted by MAAIF Uganda under aegis of FAO revealed that over half of the respondents (53.7\%) reported that HIV spread was as a result of people having multiple sexual partners \& $46 \%$ of respondents agreed that condom use would prevent HIV infection. ${ }^{16}$

Only 1935 (44.93\%), 1404 (32.60\%) and 600 $(13.93 \%)$ individuals in the present study are aware about transmission through contaminated needles and syringes, contaminated blood, and from mother to child, respectively as against the reported figures of, $72 \%, 98.5 \%$ and $83-96 \%$ respectively for the same, in other studies ${ }^{4-7}$. This may be because of only limited accessibility to the knowledge among slum dwellers in Mumbai. It is also observed in the present study that people are very hesitant to talk on the sensitive topic like HIVIAIDS, may be a social taboo, because of which almost 1499 (34.81\%) have denied to give information on modes of transmission as well as ways of prevention (560,13.00\%). More intensified IEC efforts are justified on this ground especially for the people residing in slum areas. 
In present study area, 3746 (86.99\%) individuals are aware about use of condom as one of the most important ways of prevention of transmission of HIV, followed by use of new needle among IVDUs $(748,17.37 \%)$, receiving blood from accredited blood banks $(521,12.09 \%)$ safer sex practices (abstinence \& be faithful, 431, 10\%) and PPTCT $(115,2.67 \%)$. Study conducted by Bibi et e $\left.\right|^{17}$ reveals $62 \%$ \& $41 \%$ of study subjects, aware about Condom use $\&$ receiving blood from accredited blood bank, as ways of prevention of HIV transmission respectively.

Even though the insignificant numbers, present study also reveals that there are still misconceptions regarding modes of transmission \& ways of prevention of HIV infection. These are spread of infection through staying together and sharing personal things, contaminated air or water, mosquito bite, etc., and no talk or touch with infected person, avoid kissing, use of contraceptive pills etc. Similar misconceptions are evident from the studies by Kore et el ${ }^{18}$, Gaash et el ${ }^{19}$, Lal et el ${ }^{7}$, Jaiswal et el ${ }^{20}$, Bassey et el ${ }^{11}$, Unnikrishnan et el. ${ }^{21}$ These issues deserve attention while reaching to these slum dwellers with intensified IEC efforts.

In our study $58.03 \%$ (2499/4306) respondents said that 'No nursing care should be offered to the patient with the HIV at home'. This finding is similar to the study by Gaash et el ${ }^{19}$ where $48 \%$ respondents said that AIDS patients must not be managed at home. ${ }^{12}$

In the present study application of Multinomial logistic regression analysis confirms the significant influence of age (adults \& adolescents) and education status of respondents (Educated up to primary level Vs secondary level and above) on their knowledge and positive attitudes.

\section{CONCLUSION}

Present study undertaken to assess level of knowledge and attitudes about HIVIAIDS among slum population of Mumbai, which has identification as epicentre of HIVIAIDS epidemic in India, reveals that majority of people, have heard of HIVIAIDS and are also aware about use of condom as one of the important method of prevention of infection. However, overall level of knowledge among them as assessed by composite score is low, especially among adolescents and those who are educated only up to primary level. Knowledge in relation to modes of transmission, measures of prevention and availability of nearby testing facilities deserves more attention. Level of knowledge and positive attitudes will go a long way, towards influencing behaviour of the people conducive to prevention of HIV. There is a scope to promote intensified IEC activities about HIVIAIDS especially for slum dwellers, adolescents and those with low level of education, who are difficult to reach, even though vulnerable, being dominated by migratory people, low socioeconomic profile, and reluctant to accept discussions on sensitive topic like HIV and STIs. Community based, need oriented, IEC activities to cover non student adolescents and youth would be an ideal strategy for the same.

\section{ACKNOWLEDGEMENTS}

The authors of the study are thankful to Programme Coordinators of National Service Scheme (NSS), University of Mumbai, for facilitating active involvement of NSS volunteers in this community based survey.

\section{REFERENCES}

1. UNAIDS. Geneva: AIDS epidemic update UNAIDS; December 2007-21. http:// data.unaids.org/ pub/ epislides/2007/2007_epiupdate_en.pdf.

2. National AIDS Control Organisation, New Delhi: Department of AIDS Control, Ministry of Health \& Family Welfare,2009-10, http:// www.nacoonline. org /upload/AR\%202009-10/ NACO_AR_English\% 20corrected.pdf

3. National Family Health Survey, India (NFHS-3), International Institute for Population Sciences (IIPS) and Macro International, Mumbai, India. 2005-06 (2007)

4. Sudha RT, Vijay DT, Lakshmi V. Awareness, attitudes, and beliefs of the general public towards HIVIAIDS in Hyderabad, a capital city from South India. Indian J of Commun Med 2005;59:307-316. 
5. Population First. Report on Knowledge, Attitude and Practice (KAP) Study of Adolescent Reproductive and Sexual Health (ARSH) issues among youth in Shahapur Block - Thane. (http:// www. populationfirst.org/ pthaneactivities $01 . \mathrm{html}$ )

6. Bhalla S, Chandwani $H$, Singh D, Somasundaram C. Knowledge about HIVIAIDS among senior secondary school students in Jamnagar, Gujarat. HPPI 2005; 28:178-188.

7. Lal SS, Vasan RS, Sarma PS,Thankappan KR. Knowledge and attitude of college students in Kerala towards HIVIAIDS, Sexually Transmitted Diseases \& Sexuality. Natl Med J India 2000;13:231-6

8. Sangole S, Tandale BV, Bagde PS, Thorat DM. Evaluation of impact of health education regarding HIVIAIDS on knowledge and attitude among persons living with HIV. Indian J of Commun Med 2003; 28:30-33.

9. Sarkar P, Mostofa G, Rahman M. Knowledge of transmission routes \& prevention ways of HIVIAIDS: Bangladesh context. The Soc.Sci.2010;5:525-31.

10. Sogarwal R, Bachani D. Awareness of women about STDs, HIV/AIDS and condom use in India: lessons for preventive programmes. HPPI 2009;32:148-58.

11. Bassey EA, Abasiubong F, Ekanem U, Abasiatai AM. Awareness and knowledge of HIVIAIDS at booking among antenatal clinic attendees in Uyo, Nigeria. Int J Med Med Sci 2009;1:334-38.

12. Sarkar S, Danabalan M, Kumar GA. Knowledge and attitude on HIVIAIDS among married women of reproductive age attending a teaching hospital. Indian J of Commun Med 2007;32:82-83.

13. Chakrovarty A, Nandy S, Roy R, Sengupta B, Chatterjee $S$, Chaudhuri R. A study of awareness on HIV/AIDS among higher secondary school students in Central Kolkata. Indian J of Commun Med 2007;32:228-29.
14. Singh R, Garg SK, Singh JV, Bhatnagar M, Chopra H. An awareness study about AIDS and safe blood among higher secondary girl students; Indian J Commun Med 2004;29:114.

15. Kalasagar M, Sivapathasundharam B, Einstein T, Bertin A. AIDS's awareness in an Indian metropolitan slum dweller: A KAP (knowledge, attitude, practice) study. Indian J Dent Res 2006;17:66-9

16. Ministry of Agriculture, Animal Industry and Fisheries Uganda (2002). The impact of HIVIAIDS on agricultural production and mainstreaming HIVIAIDS messages into agricultural extension in Uganda. (http:// www.fao.org/ docrep/ 005/ac912e/ ac912e00.HTM)

17. Bibi P, Panda P, Purty AJ, Bazroy J. Awareness on HIVIAIDS among Women in a Refugee Community. Indian J of Commun Med 2006;31:208-9.

18. Kore SJ, Pandole A, Nemade Y, Putharaya S. Attitude, Knowledge, beliefs about HIVIAIDS in college going adolescents. Bombay Hospital Journal 2004;46

19. Gaash B, Ahmad M, Kasur R, Bashir S. Knowledge, attitude and belief on HIVIAIDS among the female senior secondary students in Srinagar district of Kashmir. HPPI 2003;26:101-9.

20. Jaiswal S, Magar BS, Thakali K, Pradhan A, Gurubacharya DL. HIVIAIDS and STI related knowledge, attitude and practice among high school students in Kathmandu valley. KUM J 2005;3:69-75.

21. Unnikrishnan, Mithra P, Rekha T, Reshmi B. Awareness and attitude of the general public toward HIVIAIDS in coastal Karnataka. Ind $\mathrm{J}$ of Commun Med 2010;35:142 